\title{
Optical Doppler Tomography
}

National Cancer Institute

\section{Source}

National Cancer Institute. Optical Doppler Tomography. NCI Thesaurus. Code C116447.

An imaging modality that combines laser Doppler flowmetry with optical coherence

tomography to produce high-resolution tissue images that demonstrate direction and velocity of blood flow. 